\title{
Sexualidade de portadoras de estoma intestinal definitivo: percepção de mulheres
}

Recebido em 29/06/2012

Aprovado em: 27/05/2013

Ahead of print: 16/05/2014
Sérgio Ribeiro dos Santos ${ }^{1}$

Ana Lúcia de Medeiros ${ }^{2}$

Rômulo Wanderley de Lima Cabral ${ }^{3}$ Maria das Neves Silva Anselmo ${ }^{4}$ Márcia Cristina de Jesus Souza ${ }^{5}$

Resumo: $O$ estudo tem o objetivo de investigar as alterações ocorridas no modo de vida de mulheres portadoras de estoma intestinal definitivo e as repercussões na sexualidade. Pesquisa descritiva com abordagem qualitativa, realizada no Hospital Universitário de João Pessoa/PB, com dez mulheres estomizadas. Utilizou-se a técnica de análise de conteúdo de Bardin para interpretação dos dados. Os resultados demonstraram que as mulheres enfrentaram, além das mudanças no trânsito intestinal, alterações no modo de vida, afetando a autoimagem e a sexualidade. Portanto, a reflexão sobre a condição de ser estomizada é um passo inicial na busca da sensibilização e redução do preconceito.

Palavras-chave: sexualidade; estomia; percepção; mulheres.

\section{Sexuality of Patients with Intestinal Stoma Final: Perception of Women}

Abstract: The study has the aim to investigate the changes that happen in women's life when they suffer definitive intestinal stomas and their implications in their sexuality. It's about a research made in field, at the University's Hospital of João Pessoa/PB, where ten women took place at this work. The data interpretation, was adopted the technique of analysis of contents of Bardin. The results have showed that women had to face, besides the change of intestinal traffic, change in the way of life, affecting their image and sexuality. So, acording to the importance of the point dicussed, the reflection and it's effects, need extremely attention trying to reduce the prejudice.

Keywords: Sexuality; ostomy; perception; women.

\section{La Sexualidad de los Pacientes con Estoma Intestinal Final: Percepción de las Mujeres}

Resumen: El estudio tiene el objetivo de investigar las alteraciones que se pasan en la vida de mujeres portadoras de estoma intestinal definitivo y las repercusiones en la sexualidad. Pesquisa descritiva con abordaje cualitativa, realizada en el Hospital Universitario de João Pessoa/PB, con diez mujeres estomizadas. Fue utilizado la técnica de análisis de contenido de Bardin para interpretación de datos. Los resultados demostraron que las mujeres enfrentaron, además del cambio en el tránsito intestinal, alteraciones en el modo de vida, afectando la autoimagen y la sexualidad. Por eso, la reflección sobre la condición de ser estomizada es un primer paso en la búsqueda de la sensibilizar y reducir el prejuicio.

Palabras clave: sexualidad; estomía; percepción; mujeres.

\section{INTRODUÇÃO}

A Igumas doenças criam condições que interferem no trânsito das fezes pelo reto. $O$ tratamento para essas desordens consiste na necessidade de abertura artificial temporária ou permanente na parede abdominal. As aberturas cirúrgicas são criadas no íleo ou cólon com as terminações dos intestinos trazidas através da parede abdominal para criar um estoma ${ }^{(1)}$.

Portanto, os pacientes que realizam estomia geralmente apresentam grande dificuldade diante da nova situação e da mudança da imagem física. São vários os medos e receios, que vão desde a rejeição da família e amigos frente a essa situação, o não saber lidar com a estomia, a reintegração social e até a perda do emprego.

É perfeitamente compreensível, o paciente visualizar o estoma como uma mutilação, comparada com outras incisões abdominais que curam e ficam ocultas. Como existe uma perda de parte do corpo, bem como uma alteração importante na anatomia, o paciente, frequentemente, atravessa os vários estágios do pesar - choque, descrença, negação, rejeição, raiva e restituição. A preocupação com a imagem corporal pode levar a perguntas sobre as relações familiares, função sexual e, para as mulheres, sobre a capacidade de engravidar e até dar à luz um filho em condições normais(2).

Nesse contexto, podem ocorrer alterações na vida sexual da pessoa, resultando na diminuição ou perda da libido e por vezes impotência, relacionadas com a alteração da imagem do corpo e a consequente diminuição da autoestima da pessoa estomizada, bem como, de preocupações relacionadas com a eliminação de odores e fezes durante a relação sexual(3).

Portanto, a relação conjugal e sexual surge de imediato para o estomizado com grande expectativa na forma de reação e aceitação do companheiro e de como serão suas vidas.

1 Enfermeiro. Doutor em Sociologia. Professor Associado do Departamento de Enfermagem Clínica e do Programa de Pós-Graduação em Enfermagem da UFPB. Rua David Luna, 117 - Apto. 207. Brisamar - João Pessoa-PB, 58.033-090. E-mail srsantos207@gmail.com.

2 Enfermeira. Mestre em Enfermagem. Professora do Departamento de Enfermagem em Saúde da Mulher e do Programa de Pós-Graduação em Enfermagem Obstétrica da FASER.E-mail: aninhapits@gmail.com.

3 Enfermeiro. Mestre em Saúde Pública. Professor do Departamento de Enfermagem em Saúde da Mulher e do Programa de Pós-Graduação em Enfermagem Obstétrica da FASER. E-mail: romulopits@gmail.com.

4 Enfermeira. Especialista em Estomaterapia. Coordenadora do Serviço de Atenção a Saúde da Pessoa Ostomizada do Hospital Universitário Lauro Wanderley da UFPB.

E-mail: neves.ancelmo@gmail.com.

5 Enfermeira. Especializanda em Enfermagem do Trabalho. E-mail: marciacdej@hotmail.com. 
Desse modo, a sexualidade é um dos aspectos mais afetados pós-cirurgia, pois ocorrem sentimentos de vergonha, sujeira e repugnância.

Assim sendo, a família por ser o primeiro núcleo de relação do estomizado, exerce profunda influência nas reações e situações que envolvem a nova vida do estomizado, sendo determinante para a aceitação da estomia e, consequentemente, para o seu processo de reabilitação e adaptação.

Nesse cenário, a Enfermagem, pode atuar nas vertentes física, psíquica e social das pessoas, para cuidar eficazmente delas. O cuidado tão específico e continuado à pessoa estomizada deve atender a essas três vertentes. Em decorrência disso, percebe-se a importância de cuidar do estomizado em sua globalidade, já que este aspecto fará parte do seu processo de viver.

Diante da complexidade que envolve o paciente estomizado, o presente estudo se propõe a compreender as alterações que ocorrem no cotidiano de mulheres quanto à sua sexualidade, buscando resposta para o seguinte questionamento: como as mulheres portadoras de estoma intestinal definitivo vivenciam sua sexualidade?

Desse modo, o presente estudo teve como objetivo: investigar junto às mulheres portadoras de estoma intestinal definitivo, as alterações causadas no seu modo de vida e as repercussões sofridas na sua sexualidade.

\section{METODOLOGIA}

Trata-se de uma pesquisa de natureza descritiva-analítica com abordagem qualitativa, apropriada para este estudo por privilegiar significados, experiências, sentimentos, atitudes e valores dos sujeitos envolvidos.

A pesquisa foi realizada no Hospital Universitário Lauro Wanderley da Universidade Federal da Paraíba, por ser um local de referência para ostomizados, proporcionando maior possibilidade de investigá-los. O universo foi formado por mulheres portadoras de estomias intestinais definitivas atendidas nesse serviço durante o período de outubro e novembro de 2011. A amostra foi constituída por dez mulheres que aceitaram participar voluntariamente da pesquisa, após serem devidamente informadas a respeito do objetivo e assinarem o termo de consentimento livre e esclarecido, conforme estabelecido nas Diretrizes e Normas Regulamentadoras da Pesquisa Envolvendo Seres Humanos, constantes na Resolução no 196/96 do Conselho Nacional de Saúde ${ }^{(4)}$.

Antes de iniciar o processo de coleta dos dados, o projeto de pesquisa foi submetido ao Comitê de Ética em Pesquisa do Hospital Universitário Lauro Wanderley da UFPB, que aprovou o parecer do relator e emitiu a Certidão n 445/11, autorizando a pesquisa.

A coleta de dados foi realizada utilizando-se um roteiro de entrevista semiestruturado com algumas questões que visavam estimular a narração da vivência da sexualidade por essas mulheres. Quais sejam: fale-me como você percebe seu corpo após a cirurgia; fale-me como foi o retorno da atividade sexual após a cirurgia; fale-me dos prejuízos sexuais causados pela cirurgia. As entrevistas foram realizadas em profundidade, quando se percebeu que a quantidade de entrevistas era suficiente, pois os depoimentos mostraram a saturação ou exaustão de dados acerca das mudanças ocorridas no universo dessas mulheres, ou seja, da saturação dos dados, que então foram considerados suficientes para compreensão do fenômeno estudado.

A análise dos dados foi fundamentada na abordagem qualitativa de análise do conteúdo, que é uma técnica de investigação que tem por finalidade a descrição objetiva e sistemática do conteúdo manifesto da comunicação(5).

\section{RESULTADOS E DISCUSSÃO}

As participantes do estudo foram formadas por mulheres com idade entre 45 a 50 anos, sendo que $80 \%$ eram casadas. Esse grupo de mulheres possui ensino médio completo, mas uma baixa renda familiar oscilando entre 1 a 2 salários mínimos.

As entrevistas possibilitaram as colaboradoras manifestarem as suas experiências, nas quais se destacou cinco categorias temáticas: na primeira, as mulheres descreveram como percebem o corpo; na segunda evidenciram o papel que a religiosidade exerce em suas vidas; a terceira mostrou como a vida sexual e afetiva são afetadas após a cirurgia; a quarta categoria mostrou os problemas de ajustamento no retorno da atividade sexual; e por fim, a quinta categoria demonstrou que algumas mulheres superaram as dificuldades e atingiram o equilíbrio conjugal por receberem apoio incondicional do companheiro.

Os depoimentos obtidos na realização das entrevistas subsidiaram a construção das cinco categorias temáticas, apresentadas a seguir:

\section{Temática 1: Percepção do corpo}

A corporeidade humana, fruto de indagações e questionamentos de diversas áreas do conhecimento, como a antropologia, história, filosofia e as ciências da saúde, tem sua análise voltada aos aspectos sociais e culturais, em que a dimensão simbólica do corpo e suas representações pelos atores são centrais para a sua compreensão. Nesse sentido, as percepções, a gestualidade e a expressão dos sentimentos são idealizadas e construídas nas estruturas sociais e culturais. Assim sendo, as representações e os imaginários do corpo perpassam a relação que os atores têm com o mundo(6).

Na pesquisa, essa categoria mostra como as mulheres percebem seu corpo após a realização da cirurgia. Através da sua análise percebe-se que as mulheres julgam que houve alteração na estética corporal, provocando um impacto negativo em suas vidas, conforme os seguintes depoimentos: "meu corpo ficou horrível, ficou muito feio, porque eu fiquei muito cortada, muito cheia de cicatrizes" (Esmeralda). "mudou muita coisa no meu corpo, eu acho que eu não sou a mesma pessoa que eu era antigamente. A bolsa me incomoda, com essa bolsa eu me sinto feia" (Diamante).

Os recortes das falas demonstram que a confecção de um estoma leva a uma transformação pessoal, apesar de manter a sua nova condição encoberta sob as roupas, rompe com os seus esquemas anteriores e fazem o paciente sentir-se diferente das outras pessoas. $\mathrm{O}$ impacto de uma estomia na vida de qualquer indivíduo traz consequências que se refletem nos diferentes aspectos, dentre eles, o biológico, o psicológico, o social e o espiritual, sendo a alteração da autoestima uma das mais importantes ${ }^{(7)}$.

\section{Temática 2: Religiosidade, religião e doença}

Nessa categoria, verifica-se que a religiosidade exerce um papel fundamental na superação e na aceitação da nova condição de estomizado, podendo produzir alívio diante do sofrimento, contribuindo de forma positiva, conforme o relato a seguir: "no começo foi muito difícil, mas como tenho muito 
fé em Deus, ele me ajudou a aceitar e superar as dificuldades, ele me fortaleceu. Ele me deu coragem, perseverança pra que enfrentasse a vida normalmente" (Safira).

Verifica-se que a fé e a religião dessas mulheres auxiliaram no suporte para a superação dessa fase de mudanças existenciais e fisiológicas profundas em suas vidas, melhorando a maneira pela qual solucionaram ou atenuaram o sofrimento físico e psicológico.

Diante disso, percebe-se que os estomizados colocam a impossibilidade de atuarem ativamente na tomada de decisões ou na resolução de seus problemas. Há uma postura de entrega desta responsabilidade a agentes externos como Deus, pelo desenrolar dos acontecimentos e da evolução da sua recuperação. Há uma conotação de dependência, de estar à espera de uma resolução dos seus problemas ou de direcionamento da sua vida em função do poder de realização externa, que foge do seu controle(8).

Portanto, a crença em um "Ser Maior" que pode curar, ajuda os ostomizados a dar um sentido ao adoecimento, a aceitar a nova condição existencial e a relativizar a dor e as dificuldades vivenciadas, e dessa forma, Ihes permitem superar essa fase de mudanças, levando-os a se sentir mais ativos no tratamento, mais encorajados a lutar pela sobrevivência através da esperança na recuperação e/ ou cura ${ }^{(9)}$.

\section{Temática 3: Desinteresse pelos relacionamentos sexuais}

Quando abordada esta temática, verificou-se que algumas mulheres passaram a evitar o contato físico com o outro, provocando mudanças no desempenho sexual, demonstrando desinteresse pelos relacionamentos sexuais, evidenciado no relato: "perdi a vontade de ter uma pessoa comigo, por conta do problema, por mais que a gente diga: eu sou a mesma, lá no fundo é muito difícil aceitar. Encontrar uma pessoa, não passa pela minha cabeça. Imagine ele se deparando com essa bolsa, por isso, eu não me vejo mais com outra pessoa. Eu vivo a minha vida, aproveito todos os momentos, mas isso eu descartei" (Jade).

A fala acima mostra que a vida sexual da pessoa ostomizada é afetada, pois se encontra intimamente relacionada com o conceito de autoimagem e a consequente diminuição da autoestima e da percepção de atração sexual.

Portanto, "estar estomizado" representa conviver com uma diferença aparente, embora nem sempre visível, que, mesmo não gerando, necessariamente, um corpo frágil, incapaz, incompetente, dependente e improdutivo, viola os padrões de beleza, conformação, função e harmonia corporais que a sociedade apregoa, enquanto valores simbólicos essenciais; altera os papéis prévios, imprimindo novos e afeta o senso de competência, valor e significado pessoal, compondo a violação maior: da identidade ${ }^{(10)}$.

\section{Temática 4: 0 retorno da atividade sexual}

Essa temática mostra os problemas de ajustamento quanto à atividade sexual. As mulheres relataram que é difícil reassumir a atividade sexual tanto pela vergonha de sua nova imagem como por complicações cirúrgicas, conforme expressa essa situação: "o retorno da atividade sexual é difícil, pois muda muitas coisas, porque eu sinto que a gente não fica mais com aquela vontade, não relaxa, principalmente porque sente até medo, de relaxar à vontade, pra não se prejudicar. Agora no início eu tinha vergonha, botava a camisola, cobria, botava a toalha, hoje eu não tenho mais esses preconceitos" (Água marinha).

O relato aponta que, além das dificuldades que as mulheres enfrentam em relação às mudanças ocorridas em seu corpo, elas também podem enfrentar problemas relacionados com a cirurgia, alterando assim o retorno da atividade sexual. As dificuldades podem aparecer coligadas à insegurança, à eliminação involuntária dos flatos, ao odor, ao medo da bolsa estourar e ao medo de rejeição, principalmente no que se refere ao parceiro.

É perfeitamente compreensível o fato de que o estoma influencia na vida sexual da pessoa, principalmente se for uma ileostomia, pois não há o controle sobre as eliminações fecais, sobre o barulho provocado pela eliminação dos gases, além do uso da bolsa coletora ser constante e, visualmente não atraente ${ }^{(11)}$.

Nesse contexto, as mudanças que ocorrem na vida sexual são tão profundas que para as pessoas estomizadas, o ato sexual torna-se secundário, ou seja, pode ser substituído por sentimentos como amor, carinho, respeito, companheirismo e, até mesmo, atividade religiosa ${ }^{(12)}$.

\section{Temática 5: Apoio do companheiro}

$\mathrm{Na}$ fala que se segue é possível perceber que algumas mulheres receberam apoio incondicional do companheiro, pois estas possuíam um relacionamento consistente: "eu acho que o sexo, não mudou muito, pois eu tenho um marido muito compreensivo, que esteve comigo em todos os momentos. Eu não notei mudanças, apenas esperei me recuperar da cirurgia e ele entendeu muito bem esse momento" (Esmeralda).

O relato aponta que o apoio do companheiro é fundamental para o retorno e manutenção da vida sexual dessas mulheres.

Portanto, compartilhar do diagnóstico com o parceiro constitui um passo importante para auxiliar no processo de reabilitação da pessoa estomizada, pois possibilita a expressão das ansiedades e inseguranças, além da chance de solicitar e receber apoio emocional, amor, empatia, cuidados, ajudando no enfrentamento da situação e influenciando favoravelmente o seu estado de saúde. É importante que o parceiro seja envolvido no plano assistencial da pessoa estomizada desde a fase pré-operatória para o sucesso do seu processo de adaptação ao estoma ${ }^{(13)}$.

\section{CONSIDERAÇÕES FINAIS}

Pode-se perceber que ocorreram modificações significativas no modo de vida e na vivência da sexualidade após a cirurgia, a exigirem a busca de diferentes estratégias de enfrentamento das dificuldades. Essa adaptação significa ajustar toda uma vida em um novo contexto, onde algumas coisas importantes têm, muitas vezes, que serem abandonadas, substituídas ou reduzidas.

Os relatos revelaram ainda que a fé e a religião das entrevistadas auxiliaram no suporte para a superação desta fase de mudanças existenciais e fisiológicas profundas em suas vidas, melhorando a maneira pela qual solucionaram ou atenuaram o sofrimento físico e psicológico. 
A qualidade dos relacionamentos apareceu como elemento central do significado atribuído à sexualidade. Pessoas com relacionamentos estáveis a percebiam de forma positiva, como necessidade física e emocional a ser partilhada, e aquelas que não tinham uma relação sólida atribuíram significados negativos, negando ou evitando-a.

$\mathrm{Na}$ assistência à pessoa estomizada, a sexualidade é aspecto pouco abordado pelos profissionais de saúde, existindo ainda muita dificuldade de abordagem e questionamento sobre a temática, tanto por parte dos profissionais como por parte dos estomizados, contribuindo para que essas representações e significados sejam pouco conhecidos e explorados e, assim, ações específicas para o atendimento desse aspecto (sexualidade) sejam pouco contempladas nos planos assistenciais.

Diante da relevância de se refletir sobre a condição de ser ostomizado e sobre as suas repercussões físicas e emocionais, constitui-se um passo inicial na busca da sensibilização, da redução do estigma e do preconceito aos ostomizados, aspectos cruciais para prestação de cuidados humanizados, visando à reabilitação e a reintegração desses sujeitos na sociedade.

\section{Referências}

1 Potter PA, Perry AG. Fundamentos de enfermagem. 7 ed. Rio de Janeiro: Elsevier; 2009.

2 Smeltzer SC, Bare BG. Tratado de enfermagem médico-cirúrgico. Rio de Janeiro: Guanabara Koogan; 2005.

3 Cascais AFMV, Martini JG, Almeida PJS. O impacto da ostomia no processo de viver humano. Texto \& contexto enferm. 2007;16(1):163-7.

4 Ministério da Saúde (BR), Conselho Nacional de Saúde. Resolução 196, de 10 de outubro de 1996: diretrizes e normas regulamentadoras de pesquisa envolvendo seres humanos. Brasília (DF); 1996.

5 Bardin L. Análise de conteúdo. 4 ed. São Paulo: Edições 70; 2011.

6 Lê Breton D. A sociologia do corpo. 2 ed. Petrópolis, RJ: Vozes; 2007.

7 Costa IG, Maruyama SAT. Implementação e avaliação de um plano de ensino para a auto-irrigação de colostomia: estudo de caso. Rev latinoam enferm. 2004; 12(3):557-63.
8 Sonobe HM, Barichello E, Zago MMF. A visão do colostomizado sobre o uso da bolsa de colostomia. Rev bras cancerol. 2002;48(3):341-8.

9 Almeida SSL, Rezende AM, Schall VT, Modena CM. Os sentidos da corporeidade em ostomizados por câncer. Psicol estud. 2010;15(4):761-9.

10 Santos VLCG, Sawaia BB. A bolsa na mediação "estar ostomizado" - "estar profissional": análise de uma estratégia pedagógica. Rev latinoam enferm. 2000;8(3):40-50.

11 Barbutti RCS, Silva MCP, Abreu MAL. Ostomia, uma difícil adaptação. Rev socied bras psic hospit. 2008; 11(2):27-39.

12 Silva AL, Shimizu HE. A relevância da rede de apoio ao estomizado. Rev bras enferm. 2007;60(3):307-11.

13 Paula MAB, Takahashi RF, Paula PR. Os significados da sexualidade para a pessoa com estoma intestinal definitivo. Rev Bras coloproct. 2009;29(1):77-82. 